\title{
Scientific rationale for the possible inhaled corticosteroid intraclass difference in the risk of pneumonia in COPD
}

\author{
This article was published in the following Dove Press journal: \\ International Journal of COPD \\ 19 October 2017 \\ Number of times this article has been viewed
}

\author{
Christer Janson' \\ Georgios Stratelis ${ }^{1,2}$ \\ Anna Miller-Larsson ${ }^{3}$ \\ Tim W Harrison ${ }^{4}$ \\ Kjell Larsson ${ }^{5}$ \\ 'Respiratory, Allergy and Sleep \\ Research Unit, Department of \\ Medical Sciences, Uppsala University, \\ Uppsala, Sweden; ${ }^{2}$ Respiratory, \\ Inflammation and Autoimmunity, \\ AstraZeneca Nordic, Södertälje, \\ Sweden; ${ }^{3}$ Respiratory GMed, \\ AstraZeneca Gothenburg, Mölndal, \\ Sweden; ${ }^{4}$ Nottingham Respiratory \\ Research Unit, City Hospital \\ Campus, University of Nottingham, \\ Nottingham, UK; ${ }^{5}$ Lung and Airway \\ Research, National Institute of \\ Environmental Medicine, Karolinska \\ Institutet, Stockholm, Sweden
}

Correspondence: Christer Janson Respiratory, Allergy and Sleep Research Unit, Department of Medical Sciences, Uppsala University, Akademiska sjukhuset, 75185 Uppsala, Sweden Tel $+46 I 86 I I 4 \mid$ I5 $\mathrm{Fax}+46186110228$

Email christer.janson@medsci.uu.se

\begin{abstract}
Inhaled corticosteroids (ICSs) treatment combined with long-acting $\beta_{2}$-adrenoceptor agonists (LABAs) reduces the risk of exacerbations in COPD, but the use of ICSs is associated with increased incidence of pneumonia. There are indications that this association is stronger for fluticasone propionate than for budesonide. We have examined systematic reviews assessing the risk of pneumonia associated with fluticasone propionate and budesonide COPD therapy. Compared with placebo or LABAs, we found that fluticasone propionate was associated with $43 \%-78 \%$ increased risk of pneumonia, while only slightly increased risk or no risk was found for budesonide. We have evaluated conceivable mechanisms which may explain this difference and suggest that the higher pneumonia risk with fluticasone propionate treatment is caused by greater and more protracted immunosuppressive effects locally in the airways/lungs. These effects are due to the much slower dissolution of fluticasone propionate particles in airway luminal fluid, resulting in a slower uptake into the airway tissue and a much longer presence of fluticasone propionate in airway epithelial lining fluid.
\end{abstract}

Keywords: COPD, pneumonia, inhaled corticosteroids, budesonide, fluticasone

\section{Introduction}

Treatment with inhaled corticosteroids (ICSs) in combination with long-acting $\beta_{2}$-adrenoceptor agonists (LABAs) has been shown to relieve symptoms, improve quality of life, and reduce the risk of exacerbations in patients with COPD. ${ }^{1-5}$ The use of ICS/LABA combinations is considered safe and well tolerated. However, an area of potential concern is the increased incidence of pneumonia in COPD patients treated with ICSs, observed for the first time in the Towards a Revolution in COPD Health (TORCH) study published in 2007. ${ }^{4}$ There are indications of ICS intraclass differences in pneumonia risk with some evidence of a weaker association of pneumonia with budesonide than with fluticasone propionate therapy.

In randomized, controlled trials, treatment with fluticasone propionate alone or in combination with salmeterol was associated with increased prevalence of pneumonia compared with long-acting bronchodilator monotherapy (salmeterol or tiotropium) or placebo. ${ }^{4,6-8}$ This risk appeared to increase with increased lung function impairment. ${ }^{4,9}$ Most randomized controlled studies of budesonide alone or in combination with LABA (formoterol) reported no increased risk of pneumonia when compared with formoterol alone or placebo. ${ }^{1,2,10-12}$ In a study by Sharafkhaneh et al, however, an association between budesonide treatment and increased risk of pneumonia was found. ${ }^{13}$

A pooled patient-level analysis of 11 double-blind, randomized, controlled trials comparing an inhaled budesonide treatment (ie, budesonide/formoterol or budesonide) 
with a non-corticosteroid-containing comparator (formoterol or placebo), including $>10,000$ patients with COPD, was conducted. No statistically significant increase in the risk of treatment-emergent pneumonia adverse events or pneumonia serious adverse events was found with inhaled budesonidecontaining treatments compared with non-budesonidecontaining treatments; however, a small increase in risk with budesonide-containing treatment cannot be ruled out. ${ }^{14}$ To date, no randomized, prospective, head-to-head clinical trials have been conducted to compare the risk of pneumonia between budesonide and fluticasone propionate, and between-study differences in underlying pneumonia risk factors and methods for diagnosis and reporting of pneumonia could confound cross-study comparison. In the absence of direct head-to-head studies between fluticasone propionate and budesonide, information regarding potential intraclass differences in pneumonia risk has been provided from observational studies in the real-world setting, as well as from indirect comparison in meta-analyses/systematic reviews of the literature.

In an epidemiological study in a Canadian, new-user COPD population, Suissa et al found a 101\% higher risk of pneumonia in COPD patients treated with fluticasone propionate and a $17 \%$ increased risk in budesonide-treated patients when compared with controls not treated with ICSs. ${ }^{15}$ In a Swedish observational study in almost 5,500 COPD patients followed for up to 9 years (representing $>19,000$ patient years), patients treated with budesonide/formoterol were compared with matched patients treated with fluticasone/ salmeterol. The incidence of exacerbations was lower in patients treated with budesonide/formoterol, ${ }^{16}$ and the risk of pneumonia in COPD patients was 73\% higher in the fluticasone group than in the budesonide group. ${ }^{17}$ It could be argued that predefined diagnostic standards for pneumonia are lacking in most of the observational studies evaluating the association between the risk of pneumonia and ICS treatment, including the study by Janson et al. ${ }^{17}$ However, although no chest X-ray-confirmed pneumonia was registered in the study by Janson et al, the difference between fluticasone propionate and budesonide treatments in the risk of pneumonia remained the same when the data of hospitalized patients (where pneumonia was confirmed by chest X-ray) were analyzed. ${ }^{17}$

To better understand the extent of any potential intraclass difference in pneumonia risk between fluticasone propionate and budesonide in patients with COPD, we undertook a systematic review of the literature from January 1, 2010, to June 30, 2016, to identify systematic reviews/meta-analyses addressing the risk of pneumonia associated with these two ICS treatments. The methodology and results of this search are presented in Table 1. Of the 56 publications identified, 50 did not fulfill the inclusion criteria; the remaining 6 systematic reviews addressed the risk of pneumonia associated with treatment with inhaled fluticasone propionate and budesonide in comparison with placebo or LABAs in patients with COPD, and Table 1 summarizes these 6 systematic reviews. ${ }^{18-23}$ In total, this table represents 24 fluticasone propionate and 11 budesonide studies. In all 6 systematic reviews, fluticasone propionate was associated with a statistically significant increased risk of pneumonia (of $43 \%-78 \%$ ). None of the 6 systematic reviews found budesonide to be associated with an increased risk of pneumonia; however, in one of them, the risk of nonfatal serious adverse pneumonia events (requiring hospital admission) approached statistical significance (odds ratio $[\mathrm{OR}]=1.62 ; 95 \%$ confidence interval $(\mathrm{CI})=1.00,2.62) .{ }^{23}$

Within the identified systematic reviews, direct or indirect comparisons between fluticasone propionate and budesonide were sparse. In the Cochrane review by Kew and Seniukovich, an indirect comparison found no significant difference between fluticasone propionate and budesonide monotherapy in the risk of serious adverse events (pneumonia-related or all-cause) or mortality, but a higher risk of any pneumonia event (including less serious cases treated in the community) was found for fluticasone than for budesonide $(\mathrm{OR}=1.86$; $95 \% \mathrm{CI}=1.04$, 3.34; Table 1). ${ }^{23}$ In the report by Halpin et al, an indirect comparison between budesonide and fluticasone propionate found that adverse pneumonia events and serious pneumonia adverse events were lower for budesonide than for fluticasone $(\mathrm{OR}=0.47 ; 95 \% \mathrm{CI}=0.28,0.80$; and $\mathrm{OR}=0.41$; $95 \% \mathrm{CI}=0.19,0.86$, respectively). ${ }^{19}$

These indirect comparisons and meta-analyses/systematic reviews have a number of limitations that may confound data interpretation. These limitations include methodological differences in the studies, such as the definitions of pneumonia events, methods used to confirm pneumonia, drug dosages as well as imbalances in the fluticasone and budesonide groups in terms of study durations, patient numbers, and population differences in the studies. Another limitation is that the sample size is lower for budesonide than for fluticasone propionate studies, which could lead to comparative lack of power when assessing the association between the use of budesonide and pneumonia. The fluticasone propionate studies also include the TORCH study that had a 3-year duration, while all the budesonide studies were of shorter duration. Despite these limitations, the outcomes of these 
Table I Summary of 6 systematic reviews, published from 2010 to 2016, addressing the risk of pneumonia associated with inhaled therapy containing treatment with inhaled fluticasone propionate or budesonide compared with placebo or LABAs in patients with COPD

\begin{tabular}{|c|c|c|c|c|c|c|c|c|}
\hline \multirow[t]{2}{*}{ Meta-analyses } & \multirow[t]{2}{*}{ Outcome } & \multicolumn{3}{|c|}{ Fluticasone propionate } & \multicolumn{3}{|c|}{ Budesonide } & \multirow[t]{2}{*}{ Comparator } \\
\hline & & $\begin{array}{l}\text { Studies } \\
\text { (n) }\end{array}$ & $\begin{array}{l}\text { Participants } \\
\text { (n) }\end{array}$ & $\mathbf{R R}[95 \% \mathrm{Cl}]$ & $\begin{array}{l}\text { Studies } \\
\text { (n) }\end{array}$ & $\begin{array}{l}\text { Participants } \\
\text { (n) }\end{array}$ & $\mathbf{R R}[95 \% \mathrm{Cl}]$ & \\
\hline $\begin{array}{l}\text { Singh and Loke } \\
(2010)^{18}\end{array}$ & $\begin{array}{l}\text { All reported } \\
\text { pneumonia events }\end{array}$ & 16 & 15,624 & $\begin{array}{l}\mathrm{RR}=1.67 \\
{[1.47,1.89]}\end{array}$ & 7 & 6,561 & $\begin{array}{l}\mathrm{RR}=1.19 \\
{[0.92,1.53]}\end{array}$ & LABA; placebo \\
\hline \multirow[t]{2}{*}{$\begin{array}{l}\text { Halpin et al } \\
(2011)^{19}\end{array}$} & $\begin{array}{l}\text { Adverse } \\
\text { pneumonia events }\end{array}$ & 8 & 5,203 & $\begin{array}{l}\log O R=0.669 \\
\text { variance }=0.012\end{array}$ & 4 & 2,475 & $\begin{array}{l}\log O R=-0.082 ; \\
\text { variance }=0.061\end{array}$ & Placebo \\
\hline & $\begin{array}{l}\text { Serious pneumonia } \\
\text { adverse events }\end{array}$ & 7 & 5,122 & $\begin{array}{l}\log O R=0.65 I \\
\text { variance }=0.018\end{array}$ & 4 & 2,475 & $\begin{array}{l}\log O R=-0.243 \\
\text { variance }=0.128\end{array}$ & \\
\hline \multirow[t]{2}{*}{$\begin{array}{l}\text { Spencer et al } \\
(2011)^{20}\end{array}$} & $\begin{array}{l}\text { Adverse } \\
\text { pneumonia events }\end{array}$ & I & 3,093 & $\begin{array}{l}\mathrm{OR}=1.43 \\
{[1.13,1.81]}\end{array}$ & 2 & I,07| & $\begin{array}{l}\mathrm{OR}=0.84 \\
{[0.36,1.96]}\end{array}$ & LABA \\
\hline & $\begin{array}{l}\text { Serious pneumonia } \\
\text { adverse events }\end{array}$ & 4 & 4,527 & $\begin{array}{l}\mathrm{OR}=1.46 \\
{[1.12,1.92]}\end{array}$ & I & 559 & $\begin{array}{l}\mathrm{OR}=2.42 \\
{[0.40,20.16]}\end{array}$ & \\
\hline $\begin{array}{l}\text { Nannini et al } \\
(2012)^{21}\end{array}$ & $\begin{array}{l}\text { All reported } \\
\text { pneumonia events }\end{array}$ & 9 & 8,242 & $\begin{array}{l}\mathrm{OR}=1.75 \\
{[1.25,2.45]}\end{array}$ & 3 & 2,834 & $\begin{array}{l}\mathrm{OR}=1.09 \\
{[0.69,1.73]}\end{array}$ & LABA \\
\hline $\begin{array}{l}\text { Nannini et al } \\
(2013)^{22}\end{array}$ & $\begin{array}{l}\text { All reported } \\
\text { pneumonia events }\end{array}$ & 9 & 5,447 & $\begin{array}{l}\mathrm{OR}=1.76 \\
{[1.46,2.14]}\end{array}$ & 3 & 2,837 & $\begin{array}{l}\mathrm{OR}=0.92 \\
{[0.57,1.47]}\end{array}$ & Placebo \\
\hline $\begin{array}{l}\text { Kew and } \\
\text { Seniukovich }\end{array}$ & $\begin{array}{l}\text { All reported } \\
\text { pneumonia events }\end{array}$ & II & 15,377 & $\begin{array}{l}\mathrm{OR}=1.68 \\
{[1.49,1.90]}\end{array}$ & 6 & 7,011 & $\begin{array}{l}\mathrm{OR}=1.12 \\
{[0.83,1.5 \mathrm{I}]}\end{array}$ & LABA; placebo \\
\hline$(20 \mid 4)^{23, a}$ & $\begin{array}{l}\text { Serious pneumonia } \\
\text { adverse events }\end{array}$ & 17 & 19,504 & $\begin{array}{l}\mathrm{OR}=1.78 \\
{[1.50,2.12]}\end{array}$ & 7 & 6,472 & $\begin{array}{l}\mathrm{OR}=1.62 \\
{[1.00,2.62]}\end{array}$ & \\
\hline
\end{tabular}

Notes: an an indirect comparison, a higher risk of any pneumonia event (including less serious cases treated in the community) was found for fluticasone propionate than for budesonide $(\mathrm{OR}=\mathrm{I} .86 ; 95 \% \mathrm{Cl}=1.04,3.34)$. Meta-analyses identified by searching PubMed using the following search strategy: (Mesh Terms "chronic obstructive airway disease" OR "chronic obstructive lung disease" OR "chronic obstructive pulmonary disease" OR "pulmonary disease, chronic obstructive") AND "pneumonia" [All Fields] AND "budesonide" [Mesh Term] AND "fluticasone" [Text Word] AND "review" [Publication Type] AND "English" [Language] AND "20I0/0I/0I-20I6/06/30" [Date - Publication]. Only articles based on a systematic literature search were included; if more than one systematic review from the Cochrane Library was identified during the time interval, only the last report was included. Studies that reported the "total" risk, ie, the risk of pneumonia due to treatment with ICS without separating the effect of different ICSs, were excluded. Of the 56 articles identified, 50 did not meet the inclusion criteria; the remaining 6 are summarized here.

Abbreviations: $\mathrm{Cl}$, confidence interval; ICS, inhaled corticosteroid; LABA, long-acting $\beta_{2}$-adrenoceptor agonist; OR, odds ratio; RR, risk ratio.

indirect comparisons and systematic reviews are consistent with the results from observational studies assessing the risk of pneumonia with ICS use and support the hypothesis that budesonide therapy is associated with fewer pneumonia events than therapy with fluticasone propionate.

In April 2016, the European Medicines Agency Pharmacovigilance Risk Assessment Committee completed a review of the known risk of pneumonia in patients with COPD receiving ICSs and reported that they did not find any conclusive evidence of differences in the risk of pneumonia between different ICSs. ${ }^{24}$ It is, however, not clear on what scientific evidence this conclusion is based. To date, no randomized, prospective, head-to-head clinical trials are available to provide the conclusive evidence for the intraclass difference between different ICSs. However, a retrospective analysis of the large, 4-year, prospective, randomized Understanding Potential Long-term Impacts on Function with Tiotropium (UPLIFT) trial has been published recently (March 2017), evaluating differences in incidence of adverse respiratory events among patients entering the study on no ICS, on fluticasone propionate, or on other ICSs. ${ }^{25}$ The design of this study allowed the continuing effects of ICSs on respiratory adverse events to be observed prospectively in a controlled COPD population. The incident rate of pneumonia was significantly higher in patients treated with inhaled fluticasone propionate compared with those not using ICSs $(p<0.001)$ or those on other ICSs (analyzed as one group, $p<0.001$ ). The incident rate ratio was 1.38 for fluticasone propionate and $1.05(p=0.52)$ for other ICSs as compared to those not using ICSs. The investigation suggests that there are intraclass differences in the risk of pneumonia between fluticasone propionate and other ICSs. It is, however, not possible to draw conclusions on the use of budesonide and the risk of pneumonia from the study.

In summary, there are data from both observational studies in real-world clinical practice and indirect comparisons/ systematic reviews of the literature, supporting that there is an intraclass difference between fluticasone propionate and budesonide treatments in terms of pneumonia risk - with a higher risk of pneumonia for fluticasone propionate than for budesonide. This article discusses possible mechanisms for this observed difference. 


\section{Physicochemical and pharmacokinetic differences}

The use of ICSs ensures that high concentration of active drug is delivered locally to the airways and lungs with a relatively low systemic burden. After inhalation, corticosteroids are deposited as small particles on the surface of airway mucosa, and they gradually dissolve in mucosal lining fluid before they are absorbed into airway/lung tissue and target cells to exert local immunosuppression and reduction of inflammation.

The local pharmacokinetic profile of ICSs, ie, the rate and extent of airway/pulmonary absorption, is strongly dependent on the intrinsic physicochemical properties of corticosteroids, particularly lipophilicity, aqueous solubility, and airway epithelial permeability. The important determinant of dissolution rate of ICS particles in the airway epithelial lining fluid is aqueous solubility, which greatly differs between various ICSs. As the available fluid volume for dissolution in the lungs is small (lung lining fluid volume in humans is estimated to be $10-30 \mathrm{~mL}){ }^{26}$ dissolution rates for highly lipophilic corticosteroids are a rate-limiting step in the absorption from the bronchial surfaces. Among ICSs, budesonide has relatively high aqueous solubility ( $16 \mu \mathrm{g} / \mathrm{mL})$, whereas the solubility of fluticasone propionate is very low $(<0.1 \mu \mathrm{g} / \mathrm{mL}) .{ }^{27}$ Studies on dissolution rates of budesonide and fluticasone propionate (in vitro and in simulated lung fluid studied in a flow cell) show that budesonide particles were dissolved in 6 minutes, while fluticasone propionate required at least 6 hours $^{27}$ or even $>8$ hours. ${ }^{28}$ In agreement with the slow dissolution, only $6 \%-7 \%$ of fluticasone propionate deposited on human bronchial epithelial cell line (Calu-3) was absorbed through the cell monolayer during 4 hours, $93 \%-94 \%$ remained on the cell surface, ${ }^{29}$ whereas during the same time $60 \%-70 \%$ of budesonide was transported through the same cell line $e^{30,31}$ as well as through human primary alveolar epithelial cells. ${ }^{32}$ Importantly, in these in vitro studies, commercially available drug powder or suspension aerosol formulations were used for deposition of drugs on the cell surface, and the cells were cultured in air-liquid interface conditions, thus mimicking in vivo context.

The prolonged presence of fluticasone propionate in airway lumen, as compared to budesonide, was also indicated by the study in subjects who inhaled single $1,000 \mu \mathrm{g}$ doses of both budesonide and fluticasone propionate via dry powder inhalers before surgery (lung or lobar resection due to lung cancer). In this study, fluticasone propionate was detected in several bronchial brush samples for up to 18 hours after inhalation, whereas budesonide was detected only in one brush taken 2 hours after inhalation. ${ }^{33}$ Similarly, in patients with COPD, Dalby et al showed that inhaled budesonide was present in the airway lumen for a much shorter time compared with inhaled fluticasone propionate. ${ }^{34}$ This was indicated by the finding that fluticasone propionate was recovered in the spontaneously expectorated sputum over 6 hours after inhalation of salmeterol/fluticasone propionate $(50 / 500 \mu \mathrm{g})$, whereas the majority of the expectorated fraction of budesonide was recovered in the first 2 hours after inhalation of budesonide/formoterol (400/12 $\mu \mathrm{g}$ ) dose (Figure 1). ${ }^{34}$ Deposited undissolved particles of ICSs on the airway walls are exposed to clearance mechanisms by mucociliary escalator. In this study, 5 times greater amount of fluticasone propionate than that of budesonide (calculated as the percentage of estimated lung-deposited dose) was recovered in sputum collected over 6 hours, suggesting that the low dissolution rate of fluticasone propionate delays absorption of fluticasone propionate from the airway lumen.

The prolonged presence of fluticasone propionate in airway lumen is also indicated by the much longer time for systemic absorption of fluticasone propionate than that of budesonide. In COPD patients in the Dalby et al's study commented above, budesonide reached maximal concentration in plasma 15.5 minutes after inhalation compared with 50.8 minutes for fluticasone propionate. ${ }^{34}$ In patients with asthma, the mean time for systemic absorption (mean absorption time [MAT]) derived from repeated dose inhalations ( $1 \mathrm{mg}$ twice daily for 7 days) was 1 hour for budesonide (Turbuhaler ${ }^{\circledR}$; AstraZeneca, Gothenburg, Sweden) and nearly 7 hours for fluticasone propionate (Diskus ${ }^{\circledR}$; GlaxoSmithKline, Brentford, UK). ${ }^{35}$ After a single dose (1 mg via Diskhaler ${ }^{\mathbb{R}}$; GlaxoSmithKline) given to healthy subjects, the MAT determined for fluticasone propionate was 2 hours. ${ }^{36}$ Noteworthy, in the same study in healthy subjects, fluticasone furoate, a highly lipophilic ICS structurally closely related to fluticasone propionate (both containing the S-fluoromethyl carbothioate group conferring high lipophilicity), had a MAT of 7 hours; the time for $90 \%$ absorption was 11 hours for fluticasone propionate and 20-30 hours for fluticasone furoate. ${ }^{36}$ Importantly, rates of dissolution, absorption, and luminal clearance of lipophilic, slowly dissolving ICSs may be even lower in severe COPD due to emphysema (lower surface area), airway obstruction, fibrosis, and impaired mucociliary clearance. ${ }^{27}$

After absorption from the airway lumen, retention of ICSs within airway/lung tissue is determined by corticosteroid binding to the tissue, which is generally positively correlated to corticosteroid lipophilicity. However, this is different for budesonide, which, despite its only moderate lipophilicity, is retained in the airway/lung tissue for a long time. This is due to intracellular conjugation (esterification) 

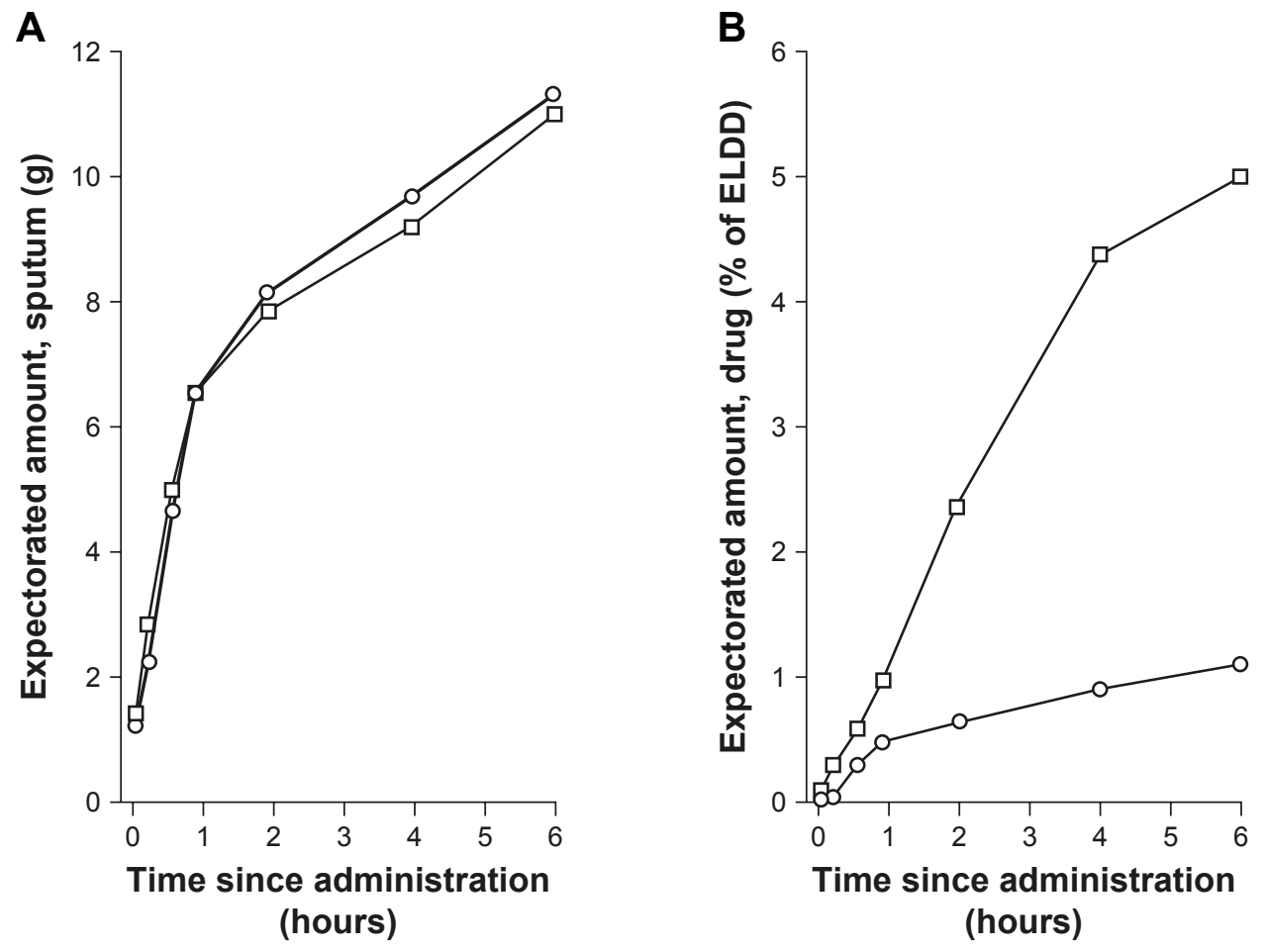

$-O-$ BUD/FORM $-\square-$ SAL/FLU

Figure I Cumulative mean amounts of expectorated sputum (A) and budesonide and fluticasone propionate (B) over 6-hour collection after inhalation of a dose of salmeterol/ fluticasone propionate (50/500 $\mu$ g via Diskus ${ }^{\circledR}$; GlaxoSmithKline, Brentford, UK) or budesonide/formoterol (400/I $2 \mu \mathrm{g}$ via Turbuhaler ${ }^{\circledR}$; AstraZeneca, Gothenburg, Sweden). Mean value plots of the amount of $(\mathbf{A})$ expectorated sputum (arithmetic means) and (B) budesonide and fluticasone propionate in the expectorated sputum (percentage of ELDD, geometric means), cumulative over the 6-hour collection period.

Notes: Reproduced from Dalby C, Polanowski T, Larsson T, Borgstrom L, Edsbacker S, Harrison TW. The bioavailability and airway clearance of the steroid component of budesonide/formoterol and salmeterol/fluticasone after inhaled administration in patients with COPD and healthy subjects: a randomized controlled trial. Respir Res. 2009; 10:104. Copyright @2009 Dalby et al; licensee BioMed Central Ltd. Creative commons license: https://creativecommons.org/licenses/by/2.0/legalcode. ${ }^{34}$

Abbreviations: BUD/FORM, budesonide/formoterol; ELDD, estimated lung-deposited dose; SAL/FLU, salmeterol/fluticasone propionate.

of budesonide with fatty acids at C-21 of the budesonide molecule, resulting in the formation of very lipophilic fatty acid esters (mostly oleate) lacking affinity to glucocorticoid receptor and thus making an inactive depot of budesonide in the target airway/lung tissue (Figure 2). ${ }^{37,38}$ Budesonide is absorbed into airway/lung tissue within minutes and is rapidly esterified; up to $70 \%-80 \%$ of budesonide is esterified in airway tissue 20 minutes after the start of 5-minute inhalation. ${ }^{37}$ Budesonide esters are gradually hydrolyzed back to active drug over an extended time period by the action of intracellular lipases and cholesterol esterases as the concentration of free/active budesonide in the cell decreases. Therefore, although budesonide is rapidly absorbed from the airway lumen, the residence time of budesonide within airway/lung tissue is similar to or even longer than that of fluticasone propionate. ${ }^{33,37}$ Budesonide esters provide a slow-release reservoir of active budesonide in the airway/ lung tissue, which explains the long duration of action of budesonide over that expected from this drug's general pharmacokinetics and moderate lipophilicity. ${ }^{37,38}$ Thus, the long residence time of budesonide within airway/lung tissue is determined by a long intracellular presence of budesonide fatty acid esters due to their very high lipophilicity. This is in contrast to fluticasone propionate; its long residence time in the airways is determined by two factors: the prolonged presence of slowly dissolving particles of fluticasone propionate in airway luminal fluid and long presence of fluticasone propionate within airway/lung tissue due to high lipophilicity of the fluticasone propionate molecule.

\section{Differences in immunosuppressive efficacy}

From a clinical perspective, fluticasone propionate is considered as a more potent corticosteroid than budesonide; clinical dose of $400 \mu \mathrm{g}$ budesonide is estimated as comparable to $250 \mu \mathrm{g}$ fluticasone propionate (1.6-fold ratio). However, fluticasone propionate was shown to be $\sim 10$ times more potent than budesonide in suppression of pro-inflammatory cytokines released by human alveolar macrophages and alveolar epithelial cells after in vitro exposure to lipopolysaccharide or 


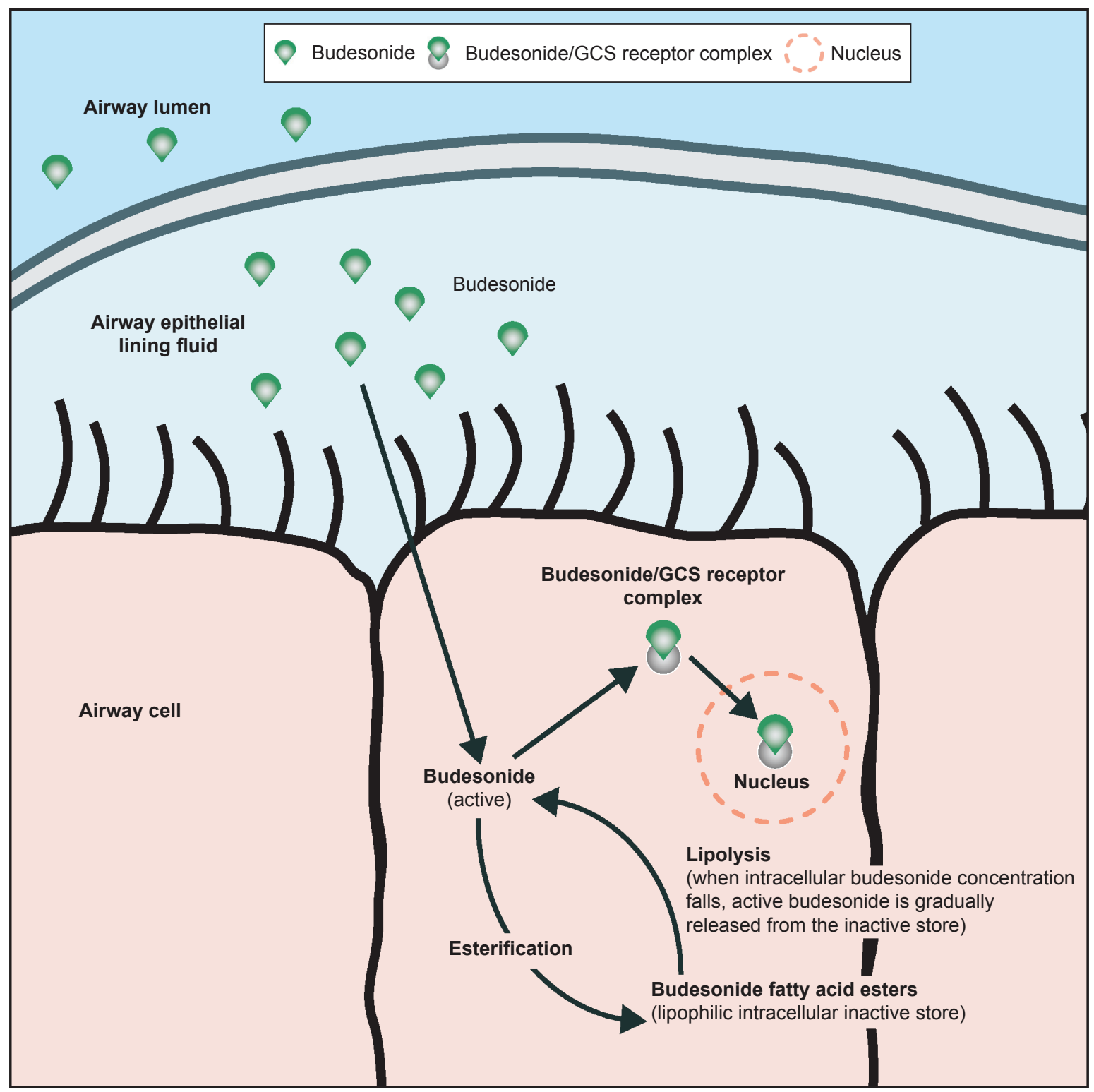

Figure 2 The reversible process of budesonide endogenous esterification with fatty acids in the airway/lung tissue, showing the intracellular depot of budesonide and illustrating the variable lipophilicity of budesonide, ie, moderate lipophilicity in the airway epithelial lining fluid and very high lipophilicity intracellularly where a portion of budesonide - not bound to GCS receptor - is reversibly converted to highly lipophilic fatty acid esters.

Notes: Adapted from Clin Ther, 25 Suppl C, Brattsand A, Miller-Larsson A. The role of intracellular esterification in budesonide once-daily dosing and airway selectivity, 28-4I, Copyright (C) 2003 Published by Elsevier Inc., with permission from Elsevier, ${ }^{38}$ which was adapted from Ann Allergy Asthma Immunol, 88(6), Edsbäcker S, Brattsand R. Budesonide fatty-acid esterification: a novel mechanism prolonging binding to airway tissue. Review of available data. 609-6I6, Copyright @ 2002 American College of Allergy, Asthma \& Immunology. Published by Elsevier Inc. All rights reserved, with permission from Elsevier. ${ }^{62}$

Abbreviation: GCS, glucocorticosteroid.

organic dust..$^{39}$ In human alveolar epithelial cells, fluticasone propionate was also 10 times more potent than budesonide in the inhibition of the activity of E-selectin promoter that contains binding sites for a number of transcription factors, including AP-1 and NF- $\mathrm{KB}$, involved in the induction of pro-inflammatory cytokines ${ }^{40}$ Several of these cytokines acutely upregulate the expression of E-selectin (cell surface adhesion protein) on endothelial cells, which contributes to the binding and extravasation of neutrophils. Likewise, in human bronchial epithelial cells, fluticasone propionate was 80 times more potent than budesonide in the repression of vascular cell adhesion molecule-1 (VCAM-1) that plays a role in the activation and recruitment of leukocytes into infection and inflammatory sites. ${ }^{41}$ Fluticasone propionate thus might be 10-100 times more potent than budesonide as an inhibitor of local inflammation and as a suppressor of the local host immune response in the airways and lungs. Of note, in vivo, a 10-fold higher efficacy of fluticasone propionate together with the 5 -fold higher concentration of fluticasone in sputum, as detected in Dalby et al's study, ${ }^{34}$ 
may mean a 50-fold greater efficacy/immunosuppression in luminal immune cells compared with what is attained by budesonide.

Noteworthy, fluticasone furoate is an even more potent corticosteroid than fluticasone propionate as shown in vitro ${ }^{42}$ and in vivo. ${ }^{43} \mathrm{~A}$ recent systematic review of 6 randomized, placebo-controlled trials of $>8$ weeks of duration, in 15,515 patients with moderate-to-very severe stable COPD, showed that fluticasone furoate alone or in combination with a LABA vilanterol is associated with a significant increased risk of pneumonia in comparison with vilanterol. ${ }^{44}$ Although the mechanism behind this association is unknown, it is notable that fluticasone furoate also has a longer duration of anti-inflammatory action and a greater efficacy than fluticasone propionate even under oxidative stress conditions. ${ }^{42}$ Importantly, in a response to pathogen invasion, inflammatory response is built up to stop progression of infection. Fluticasone propionate and fluticasone furoate via their local increased anti-inflammatory and immunosuppressive effects might be very potent in the impairment of bacterial clearance from the airways.

\section{Effects on the systemic host defense}

ICSs due to their anti-inflammatory and immunosuppressive effects may impair local and/or systemic host defense. Since an inflammatory response is mounted against invading pathogens, ICSs may promote respiratory infections, especially in subjects with weakened immune system in the airways and lungs, such as COPD patients. However, systemic corticosteroids have been shown in several recent studies to have beneficial effects on community-acquired pneumonia, such as faster recovery, earlier hospital discharge, and decreased treatment failure. ${ }^{45-47}$ These beneficial effects were confirmed in the recent meta-analysis comprising 13 randomized controlled trials and 2,005 patients. ${ }^{48}$ Therefore, it seems that enhanced risk of pneumonia by ICSs in COPD patients, and differences in pneumonia risk between various ICSs, is not due to the ICS effects on systemic host defense, but on local defense in the airways and lungs.

\section{Local bronchial immunity - the link to the development of pneumonia associated with ICS use}

Immunocompetent cells of the innate defense system in the lungs, such as neutrophils and macrophages, have an important role in maintaining the normal, balanced microbial environment within the lungs. However, airway/lung colonization with various pathogenic bacteria such as Haemophilus influenzae, Streptococcus pneumoniae, and Moraxella catarrhalis is found in up to $30 \%$ of COPD patients with stable disease and in $>50 \%$ of patients during COPD exacerbations. ${ }^{49,50}$

In stable COPD patients, higher airway bacterial load was shown to be significantly correlated to higher ICS dosage, and this relationship remained significant in a multivariate analysis including age, smoking status, and $\mathrm{FEV}_{1} \%$ predicted.$^{51}$ Furthermore, it was shown that ICS use may alter the airway microbiota composition. ${ }^{52,53}$ Importantly, according to the "keystone pathogen" hypothesis, even small alterations in the abundance of a few bacterial species can have great effects on microbial community and subsequently modify disease status. ${ }^{54}$ The prolonged presence of slowly dissolving particles of fluticasone propionate in the airway epithelial lining fluid compared with budesonide may cause a protracted local immunosuppression. This could impair clearance of airway pathogens, leading to airway/lung colonization with pathogens, which may further develop to pneumonia.

The first-line defense against inhaled pathogens is airway epithelial cells. Recently, it was shown that budesonide (16 $\mathrm{nM}$ ) fully protected human bronchial epithelial barrier against damage from cigarette smoke and viral mimetic in the presence of smoke, whereas fluticasone propionate $(10 \mathrm{nM})$ had no effect. ${ }^{55}$ In the same study, adhesion and/or internalization of $S$. pneumoniae, administered to the apical side of the human bronchial epithelial cells, was doubled by concomitant exposure to viral mimetic. This increase was prevented by treatment with budesonide, but not with fluticasone propionate. Furthermore, preliminary results from a recent study by the same investigator group show that exposure of human bronchial epithelial cells to budesonide for 2 hours followed by exposure to rhinovirus resulted in significantly higher expression of several immune defense genes compared with the treatment with fluticasone propionate. ${ }^{56}$ Differential effects of budesonide and fluticasone propionate were also recently reported on bacterial recognition receptors in macrophages derived from blood monocytes of COPD subjects. Preliminary results show that budesonide prevented receptor reductions induced by both $S$. pneumoniae and non-typeable $H$. influenzae, while fluticasone propionate affected only reductions induced by $S$. pneumoniae..$^{57}$ The authors of these reports concluded that differential regulation of immune defense genes in human bronchial epithelial cells ${ }^{56}$ and bacterial pathogen recognition receptors on macrophages ${ }^{57}$ may help to explain the difference between fluticasone propionate and budesonide with respect to the risk of pneumonia. Mechanisms responsible for these differences in gene regulation are not clear; however, recently, it was shown that different corticosteroids express a unique gene "fingerprint", ${ }^{58}$ which 
could explain some differences between effects of fluticasone propionate and budesonide.

Airway and alveolar macrophages are host defense key cells responsible for the removal of inhaled pathogens and particles from the respiratory tract through their capacity to phagocytose and subsequently kill microorganisms. This is highly relevant because respiratory infections markedly contribute to the progression of COPD by way of infectious exacerbations and pneumonia. In COPD, alveolar macrophages and macrophages derived from blood monocytes have an impaired ability to phagocytose and kill respiratory pathogens, which may contribute to the increased bacterial colonization in COPD. ${ }^{59-61}$ In the study described above, ${ }^{57}$ where bacterial recognition receptors in macrophages derived from blood monocytes of COPD subjects were differently affected by budesonide and fluticasone propionate, phagocytosis of bacteria was not studied. However, in the study by Taylor et al, phagocytosis of $S$. pneumoniae and $H$. influenzae by macrophages derived from blood monocytes from COPD patients was increased when cells were treated with budesonide. ${ }^{61}$ This effect increased with budesonide concentration, and 3-fold and 5-fold increases of phagocytosis of S. pneumoniae and H. influenzae, respectively, were obtained at $1 \mu \mathrm{M}$ of budesonide. ${ }^{61}$

The functional in vitro studies described above, ${ }^{55-57}$ comparing the effects of budesonide and fluticasone propionate in bronchial epithelial cells and macrophages, were performed with dissolved corticosteroids. Thus, it was not taken into account that fluticasone propionate remains in the airway epithelial lining fluid in the form of particles for many hours after inhalation, while budesonide is dissolved within minutes. Similar to environmental particles, particles of lipophilic ICSs persisting in airway epithelial lining fluid, will be recognized by airway/alveolar macrophages and phagocytosed. Phagocytosis of fluticasone propionate particles by airway/ alveolar macrophages might lead to very high concentrations of fluticasone propionate within the phagolysosomes, and this may impair macrophage functions, including phagocytosis and killing of bacteria. This may result in impaired and delayed clearance of bacteria from the airways. The issue of phagocytosis of fluticasone propionate particles would be adequately addressed in studies in vivo with fluticasone propionate administered as powder or suspension into the airways. Thus, further studies are warranted to address the issue of phagocytosis of slowly dissolving lipophilic ICSs, which persist in the airways for many hours, and to answer whether and how it may affect susceptibility to respiratory infections.

A summary of the different mechanisms that may explain the intraclass difference in the risk of pneumonia between
Table 2 A summary of mechanisms that may explain the intraclass difference in risk of pneumonia between budesonide and fluticasone propionate

\begin{tabular}{|c|c|c|c|}
\hline \multirow[t]{2}{*}{ Mechanisms } & \multirow[t]{2}{*}{ ICS difference } & \multicolumn{2}{|c|}{ References } \\
\hline & & In vitro & In vivo \\
\hline \multicolumn{4}{|l|}{ Physicochemical properties } \\
\hline Lipophilicity & Higher for FLU & 28 & \\
\hline Aqueous solubility & Higher for BUD & 27 & \\
\hline Dissolution rate in lung lining fluid & Higher for BUD & 27,28 & 33,34 \\
\hline \multicolumn{4}{|l|}{ Airway pharmacokinetics } \\
\hline Airway epithelial absorption & Higher for BUD & $29-32$ & \\
\hline Rate of airway absorption & Faster for BUD & & 33,34 \\
\hline $\begin{array}{l}\text { Intracellular esterification } \\
\text { in airway/lung tissue }\end{array}$ & Only for BUD & & 37,38 \\
\hline \multicolumn{4}{|l|}{ Immunosuppressive effects } \\
\hline $\begin{array}{l}\text { Suppression of pro-inflammatory } \\
\text { cytokines and leukocyte adhesion } \\
\text { molecules }\end{array}$ & Higher for FLU & $39-41$ & \\
\hline \multicolumn{4}{|l|}{ Effects on local immunity } \\
\hline $\begin{array}{l}\text { Protection of airway epithelial } \\
\text { barrier }\end{array}$ & Higher for BUD & 55 & \\
\hline $\begin{array}{l}\text { Expression of immune defense } \\
\text { genes in airway epithelial cells }\end{array}$ & Higher for BUD & 56 & \\
\hline $\begin{array}{l}\text { Prevention of adhesion and/or } \\
\text { internalization of bacteria to } \\
\text { airway epithelial cells }\end{array}$ & Higher for BUD & 55 & \\
\hline $\begin{array}{l}\text { Prevention of bacteria-induced } \\
\text { reduction of bacterial recognition } \\
\text { receptors in COPD macrophages }\end{array}$ & Higher for BUD & 57 & \\
\hline $\begin{array}{l}\text { Phagocytosis of bacteria by } \\
\text { COPD macrophages }\end{array}$ & $\begin{array}{l}\text { Increased for } \\
\text { BUD }\end{array}$ & 61 & \\
\hline
\end{tabular}

Abbreviations: BUD, budesonide; FLU, fluticasone propionate; ICS, inhaled corticosteroid.

budesonide and fluticasone propionate is presented in Table 2 .

\section{Conclusion}

We suggest that the observed difference in the risk of pneumonia between fluticasone propionate and budesonide is due to greater and more protracted immunosuppressive effects of fluticasone propionate locally in the airways/lungs. This is at least partly explained by the difference between these drugs' local pharmacokinetics in the airways/lungs, where slowly dissolving particles of fluticasone propionate persist for many hours in the airway lining fluid, while budesonide is absorbed into the airway tissue within minutes. Local immunosuppression by fluticasone propionate may enhance susceptibility to respiratory infections and increase the load of pathogenic microbiome in the airways and lungs, and this may further lead to pneumonia.

\section{Disclosure}

$\mathrm{CJ}$ has served in an advisory board and/or served as a speaker and/or participated in education arranged from AstraZeneca, 
Boehringer Ingelheim, GlaxoSmithKline, Novartis, Chiesi, and TEVA. KL has served in an advisory board and/or served as a speaker and/or participated in education arranged by AstraZeneca, Boehringer Ingelheim, GlaxoSmithKline, Meda, Takeda, Novartis, and Pfizer. TWH has served in an advisory board and/or served as a speaker and/or participated in education arranged from AstraZeneca, Boehringer Ingelheim, NaPP, Vectura, TEVA, and Roche. GS is a fulltime employee of AstraZeneca Nordic. AML is a fulltime employee of AstraZeneca Gothenburg and holds AstraZeneca shares. The authors report no other conflicts of interest in this work.

\section{References}

1. Szafranski W, Cukier A, Ramirez A, et al. Efficacy and safety of budesonide/formoterol in the management of chronic obstructive pulmonary disease. Eur Respir J. 2003;21(1):74-81.

2. Calverley PM, Boonsawat W, Cseke Z, Zhong N, Peterson S, Olsson H. Maintenance therapy with budesonide and formoterol in chronic obstructive pulmonary disease. Eur Respir J. 2003;22(6):912-919.

3. Kardos P, Wencker M, Glaab T, Vogelmeier C. Impact of salmeterol/ fluticasone propionate versus salmeterol on exacerbations in severe chronic obstructive pulmonary disease. Am J Respir Crit Care Med. 2007;175(2):144-149.

4. Calverley PM, Anderson JA, Celli B, et al. Salmeterol and fluticasone propionate and survival in chronic obstructive pulmonary disease. N Engl J Med. 2007;356(8):775-789.

5. Worth H, Forster K, Eriksson G, Nihlen U, Peterson S, Magnussen H. Budesonide added to formoterol contributes to improved exercise tolerance in patients with COPD. Respir Med. 2010;104(10):1450-1459.

6. Ferguson GT, Anzueto A, Fei R, Emmett A, Knobil K, Kalberg C. Effect of fluticasone propionate/salmeterol (250/50 microg) or salmeterol (50 microg) on COPD exacerbations. Respir Med. 2008;102(8): 1099-1108.

7. Anzueto A, Ferguson GT, Feldman G, et al. Effect of fluticasone propionate/salmeterol $(250 / 50)$ on COPD exacerbations and impact on patient outcomes. COPD. 2009;6(5):320-329.

8. Wedzicha JA, Calverley PM, Seemungal TA, et al. The prevention of chronic obstructive pulmonary disease exacerbations by salmeterol/ fluticasone propionate or tiotropium bromide. Am J Respir Crit Care Med. 2008;177(1):19-26.

9. Jenkins CR, Jones PW, Calverley PM, et al. Efficacy of salmeterol/ fluticasone propionate by GOLD stage of chronic obstructive pulmonary disease: analysis from the randomised, placebo-controlled TORCH study. Respir Res. 2009;10:59.

10. Rennard SI, Tashkin DP, McElhattan J, et al. Efficacy and tolerability of budesonide/formoterol in one hydrofluoroalkane pressurized metereddose inhaler in patients with chronic obstructive pulmonary disease: results from a 1-year randomized controlled clinical trial. Drugs. 2009; 69(5):549-565.

11. Tashkin DP, Rennard SI, Martin P, et al. Efficacy and safety of budesonide and formoterol in one pressurized metered-dose inhaler in patients with moderate to very severe chronic obstructive pulmonary disease: results of a 6-month randomized clinical trial. Drugs. 2008;68(14): 1975-2000.

12. Pauwels RA, Lofdahl CG, Laitinen LA, et al. Long-term treatment with inhaled budesonide in persons with mild chronic obstructive pulmonary disease who continue smoking. European Respiratory Society Study on Chronic Obstructive Pulmonary Disease. N Engl J Med. 1999; 340(25):1948-1953.

13. Sharafkhaneh A, Southard JG, Goldman M, Uryniak T, Martin UJ. Effect of budesonide/formoterol pMDI on COPD exacerbations: a doubleblind, randomized study. Respir Med. 2012;106(2):257-268.
14. Hollis S, Jorup C, Lythgoe D, Martensson G, Regnell P, Eckerwall G Risk of pneumonia with budesonide-containing treatments in COPD: an individual patient-level pooled analysis of interventional studies. Int J Chron Obstruct Pulmon Dis. 2017;12:1071-1084.

15. Suissa $S$, Patenaude V, Lapi F, Ernst P. Inhaled corticosteroids in COPD and the risk of serious pneumonia. Thorax. 2013;68(11):1029-1036.

16. Larsson K, Janson C, Lisspers K, et al. Combination of budesonide/ formoterol more effective than fluticasone/salmeterol in preventing exacerbations in chronic obstructive pulmonary disease: the PATHOS study. J Intern Med. 2013;273(6):584-594.

17. Janson C, Larsson K, Lisspers KH, et al. Pneumonia and pneumonia related mortality in patients with COPD treated with fixed combinations of inhaled corticosteroid and long acting beta 2 agonist: observational matched cohort study (PATHOS). BMJ. 2013;346:f3306.

18. Singh S, Loke YK. Risk of pneumonia associated with long-term use of inhaled corticosteroids in chronic obstructive pulmonary disease: a critical review and update. Curr Opin Pulm Med. 2010;16(2):118-122.

19. Halpin DM, Gray J, Edwards SJ, Morais J, Singh D. Budesonide/ formoterol vs. salmeterol/fluticasone in COPD: a systematic review and adjusted indirect comparison of pneumonia in randomised controlled trials. Int J Clin Pract. 2011;65(7):764-774.

20. Spencer S, Karner C, Cates CJ, Evans DJ. Inhaled corticosteroids versus long-acting beta(2)-agonists for chronic obstructive pulmonary disease. Cochrane Database Syst Rev. 2011;(12):CD007033.

21. Nannini LJ, Lasserson TJ, Poole P. Combined corticosteroid and longacting beta(2)-agonist in one inhaler versus long-acting beta(2)-agonists for chronic obstructive pulmonary disease. Cochrane Database Syst Rev. 2012;(9):CD006829.

22. Nannini LJ, Poole P, Milan SJ, Holmes R, Normansell R. Combined corticosteroid and long-acting beta(2)-agonist in one inhaler versus placebo for chronic obstructive pulmonary disease. Cochrane Database Syst Rev. 2013;(11):CD003794.

23. Kew KM, Seniukovich A. Inhaled steroids and risk of pneumonia for chronic obstructive pulmonary disease. Cochrane Database Syst Rev. 2014;(3):CD010115.

24. European Medicines Agency. PRAC reviews known risk of pneumonia with inhaled corticosteroids for chronic obstructive pulmonary disease; 2016. Available from: http://www.ema.europa.eu/ ema/index.jsp?curl=pages/medicines/human/referrals/Inhaled_ corticosteroids_for_chronic_obstructive_pulmonary_disease/human referral_prac_000050.jsp\&mid=WC0b01ac05805c516f. Accessed September 27, 2016.

25. Morjaria JB, Rigby A, Morice AH. Inhaled corticosteroid use and the risk of pneumonia and COPD exacerbations in the UPLIFT study. Lung. 2017;195:281-288.

26. Patton JS, Brain JD, Davies LA, et al. The particle has landedcharacterizing the fate of inhaled pharamceuticals. J Aerosol Med Pulm Drug Deliv. 2010;23 (Suppl 2):S71-S87.

27. Edsbacker S, Wollmer P, Selroos O, Borgstrom L, Olsson B, Ingelf J. Do airway clearance mechanisms influence the local and systemic effects of inhaled corticosteroids? Pulm Pharmacol Ther. 2008;21(2):247-258.

28. Johnson M. Pharmacodynamics and pharmacokinetics of inhaled glucocorticoids. J Allergy Clin Immunol. 1996;97(1 Pt 2):169-176.

29. Haghi M, Traini D, Postma DS, Bebawy M, Young PM. Fluticasone uptake across Calu- 3 cells is mediated by salmeterol when deposited as a combination powder inhaler. Respirology. 2013;18(8):1197-1201.

30. Bur M, Rothen-Rutishauser B, Huwer H, Lehr CM. A novel cell compatible impingement system to study in vitro drug absorption from dry powder aerosol formulations. Eur J Pharm Biopharm. 2009;72(2):350-357.

31. Hein S, Bur M, Schaefer UF, Lehr CM. A new Pharmaceutical Aerosol Deposition Device on Cell Cultures (PADDOCC) to evaluate pulmonary drug absorption for metered dose dry powder formulations. Eur J Pharm Biopharm. 2011;77(1):132-138.

32. Haghi M, Hittinger M, Zeng Q, et al. Mono- and cocultures of bronchial and alveolar epithelial cells respond differently to proinflammatory stimuli and their modulation by salbutamol and budesonide. Mol Pharm. 2015;12(8):2625-2632. 
33. van den Brink KI, Boorsma M, Staal-van den Brekel AJ, Edsbacker S, Wouters EF, Thorsson L. Evidence of the in vivo esterification of budesonide in human airways. Br J Clin Pharmacol. 2008;66(1):27-35.

34. Dalby C, Polanowski T, Larsson T, Borgstrom L, Edsbacker S, Harrison TW. The bioavailability and airway clearance of the steroid component of budesonide/formoterol and salmeterol/fluticasone after inhaled administration in patients with COPD and healthy subjects: a randomized controlled trial. Respir Res. 2009;10:104.

35. Thorsson L, Edsbacker S, Kallen A, Lofdahl CG. Pharmacokinetics and systemic activity of fluticasone via Diskus and pMDI, and of budesonide via Turbuhaler. Br J Clin Pharmacol. 2001;52(5):529-538.

36. Allen A, Bareille PJ, Rousell VM. Fluticasone furoate, a novel inhaled corticosteroid, demonstrates prolonged lung absorption kinetics in man compared with inhaled fluticasone propionate. Clin Pharmacokinet. 2013;52(1):37-42.

37. Miller-Larsson A, Mattsson H, Hjertberg E, Dahlback M, Tunek A, Brattsand R. Reversible fatty acid conjugation of budesonide. Novel mechanism for prolonged retention of topically applied steroid in airway tissue. Drug Metab Dispos. 1998;26(7):623-630.

38. Brattsand R, Miller-Larsson A. The role of intracellular esterification in budesonide once-daily dosing and airway selectivity. Clin Ther. 2003; 25 (Suppl C):C28-C41.

39. Ek A, Larsson K, Siljerud S, Palmberg L. Fluticasone and budesonide inhibit cytokine release in human lung epithelial cells and alveolar macrophages. Allergy. 1999;54(7):691-699.

40. Ray KP, Farrow S, Daly M, TalabotF, Searle N. Induction of the E-selectin promoter by interleukin 1 and tumour necrosis factor alpha, and inhibition by glucocorticoids. Biochem J. 1997;328(Pt 2):707-715.

41. Atsuta J, Plitt J, Bochner BS, Schleimer RP. Inhibition of VCAM-1 expression in human bronchial epithelial cells by glucocorticoids. Am J Respir Cell Mol Biol. 1999;20(4):643-650.

42. Rossios C, To Y, To M, et al. Long-acting fluticasone furoate has a superior pharmacological profile to fluticasone propionate in human respiratory cells. Eur J Pharmacol. 2011;670(1):244-251.

43. Salter M, Biggadike K, Matthews JL, et al. Pharmacological properties of the enhanced-affinity glucocorticoid fluticasone furoate in vitro and in an in vivo model of respiratory inflammatory disease. Am J Physiol Lung Cell Mol Physiol. 2007;293(3):L660-L667.

44. Rodrigo GJ, Neffen H. A systematic review with meta-analysis of fluticasone furoate/vilanterol combination for the treatment of stable COPD. Pulm Pharmacol Ther. 2017;42:1-6.

45. Annane D. Corticosteroids and pneumonia: time to change practice. Lancet. 2015;385(9977):1484-1485.

46. Blum CA, Nigro N, Briel M, et al. Adjunct prednisone therapy for patients with community-acquired pneumonia: a multicentre, double-blind, randomised, placebo-controlled trial. Lancet. 2015;385(9977):1511-1518.

47. Torres A, Sibila O, Ferrer M, et al. Effect of corticosteroids on treatment failure among hospitalized patients with severe community-acquired pneumonia and high inflammatory response: a randomized clinical trial. JAMA. 2015;313(7):677-686.
48. Siemieniuk RA, Meade MO, Alonso-Coello P, et al. Corticosteroid therapy for patients hospitalized with community-acquired pneumonia: a systematic review and meta-analysis. Ann Intern Med. 2015;163(7): 519-528.

49. Sethi S, Maloney J, Grove L, Wrona C, Berenson CS. Airway inflammation and bronchial bacterial colonization in chronic obstructive pulmonary disease. Am J Respir Crit Care Med. 2006;173(9):991-998.

50. Sethi S, Murphy TF. Infection in the pathogenesis and course of chronic obstructive pulmonary disease. N Engl J Med. 2008;359(22): 2355-2365.

51. Garcha DS, Thurston SJ, Patel AR, et al. Changes in prevalence and load of airway bacteria using quantitative PCR in stable and exacerbated COPD. Thorax. 2012;67(12):1075-1080.

52. Huang YJ, Sethi S, Murphy T, Nariya S, Boushey HA, Lynch SV. Airway microbiome dynamics in exacerbations of chronic obstructive pulmonary disease. J Clin Microbiol. 2014;52(8):2813-2823.

53. Pragman AA, Kim HB, Reilly CS, Wendt C, Isaacson RE. The lung microbiome in moderate and severe chronic obstructive pulmonary disease. PLoS One. 2012;7(10):e47305.

54. Hajishengallis G, Darveau RP, Curtis MA. The keystone-pathogen hypothesis. Nat Rev Microbiol. 2012;10(10):717-725.

55. Heijink IH, Jonker MR, de Vries M, et al. Budesonide and fluticasone propionate differentially affect the airway epithelial barrier. Respir Res. 2016;17:2.

56. Heijink I, Jonker M, Postma D, Van den Berge M. Differential effects of budesonide and fluticasone propionate on immune defense genes in human bronchial epithelium. Eur Respir J. 2015;46 (Suppl 59): PA2558.

57. Provost KA, Smith M, Miller-Larsson A, Gudleski GD, Sethi S. Bacterial regulation of pathogen recognition receptors in macrophages in COPD are differentially modified by budesonide and fluticasone propionate ex vivo. Am J Respir Crit Care Med. 2016;193:A6335.

58. Joshi T, Johnson M, Newton R, Giembycz M. An analysis of glucocorticoid receptor-mediated gene expression in BEAS-2B human airway epithelial cells identifies distinct, ligand-directed, transcription profiles with implications for asthma therapeutics. Br J Pharmacol. 2015;172: 1360-1378.

59. Donnelly LE, Barnes PJ. Defective phagocytosis in airways disease. Chest. 2012;141:1055-1062.

60. Berenson CS, Garlipp MA, Grove LJ, Maloney J, Sethi S. Impaired phagocytosis of nontypeable Haemophilus influenzae by human alveolar macrophages in chronic obstructive pulmonary disease. J Infect Dis. 2006;194(10):1375-1384

61. Taylor AE, Finney-Hayward TK, Quint JK, et al. Defective macrophage phagocytosis of bacteria in COPD. Eur Respir J. 2010;35(5): 1039-1047.

62. Edsbäcker S, Brattsand R. Budesonide fatty-acid esterification: a novel mechanism prolonging binding to airway tissue. Review of available data. Ann Allergy Asthma Immunol. 2002;88(6):609-616.
International Journal of COPD

\section{Publish your work in this journal}

The International Journal of COPD is an international, peer-reviewed journal of therapeutics and pharmacology focusing on concise rapid reporting of clinical studies and reviews in COPD. Special focus is given to the pathophysiological processes underlying the disease, intervention programs, patient focused education, and self management protocols.
Dovepress

This journal is indexed on PubMed Central, MedLine and CAS. The manuscript management system is completely online and includes a very quick and fair peer-review system, which is all easy to use. Visit $\mathrm{http}: / / \mathrm{www}$. dovepress.com/testimonials.php to read real quotes from published authors. 